\title{
Effect of aging and solution annealing on transformation and deformation mechanism of super-elastic Ni50.9\%-Ti alloy in nano-scale
}

\author{
A. Ghabchi ${ }^{\text {a, } 1,2,3}$, J. Khalil-Allafi ${ }^{1}$, X.W. Liu ${ }^{4}$, O. Söderberg ${ }^{4}$, E. Turunen ${ }^{2}$, S-P Hannula ${ }^{4}$ \\ ${ }^{1}$ Sahand University of Technology, Department of Materials Engineering, Tabriz, Iran \\ ${ }^{2}$ Technical Research Center of Finland (VTT), Espoo, Finland \\ ${ }^{3}$ Center for Thermal Spray Research, Material Science and Engineering Department, SUNY, Stony Brook, USA \\ ${ }^{4}$ Department of Materials Science and Engineering, Helsinki University of Technology, Espoo, Finland
}

\begin{abstract}
Effects of aging and solution annealing treatment on the super elastic respond of the cold-worked Ni50.9\%-Ti thin wire was studied in nano-scale utilizing instrumented nanoindentation. The nanoindentation results were coupled with the tensile test results to provide better insight to the governing deformation mechanisms. The first applied heat treatment consisted of solution annealing treatment $\left(850^{\circ} \mathrm{C}\right.$ for 60 minutes) followed by aging at $450^{\circ} \mathrm{C}$ for 30 minutes and as second heat treatment the cold-worked wire was aged at $450^{\circ} \mathrm{C}$ for 30 minutes with no prior solution annealing treatment. Both tensile test and nanoindentation results showed better super elastic behavior for the wire subjected to second treatment. Indentation displacement bursts were observed in loading course after both treatments. However, slope changes in unloading course of indents were recorded after second heat treatment which might be due to reverse phase transformation. Surface asperities on the post-indented surface after first treatment were observed far away from indentation stress field by atomic force microscopy.
\end{abstract}

\section{Introduction}

Micro- and nanoelectromechanical (MEMS and NEMS) systems are gaining great interest in wide variety of industries as actuators and sensors. Nevertheless, for any materials developed for this purpose there is a question of reliability in operation and manufacturing while the size of the material is decreasing to sub-micron or nano-scale. Another deficiency which rises from decreasing the size scale is the amount of output work. Application of martensitic materials can be a solution to overcome such intrinsic issues. Krulevitch et al. demonstrated that a NiTi actuator has the highest work output among other actuator materials [1]. Thus, the martensitic transformation can be exploited as stress-induced in super-elasticity and as thermally induced in one way or two way shape memory effect, provides more flexibility in designing smart MEMS [2]. Characterization of stress induced martensitic (SIM) transformation in nanoscale is a challenging task to accomplish. One potential technique to understand the SIM in nanoscale is nanoindentation. Nanoindentation returns the continuous indentation load-displacement response of a material with resolution of micronewton in load and nano-meter in depth. This technique provides a unique tool for studying the local mechanical properties as well as insight into the associated deformation mechanism in that scale [3]. The nanoindentation technique has been used for characterization of martensitic materials [4-6], but information of studies with bulk material is limited. However, even for a simple material structure, interpretation of load-displacement response is not a trivial task due to the complexity of stress field in the volume of material and the possible different deformation mechanisms, not to mention the complexity of the crystal structure or the effect of the possible special surface layers, such as oxides.

In this study we address the deformation mechanisms in Ni-rich NiTi wires under tensile tests and nanoindentation. As the tensile test samples the whole bulk volume, nanoindentation returns the response of material only from few hundreds nanometers volume of material. Different phases in the studied material were obtained by applying different heat treatments in order to study their influence on deformation mechanisms. The surfaces, before and after nanoindentation were studied by atomic force microscopy (AFM).

${ }^{a}$ e-mail: Arash. Ghabchievtt.fi

This is an Open Access article distributed under the terms of the Creative Commons Attribution-Noncommercial License (http://creativecommons.org/licenses/by-nc/3.0/), which permits unrestricted use, distribution, and reproduction in any noncommercial medium, provided the original work is properly cited. 


\section{Experimental}

\subsection{Materials and heat treatments}

The thin wires (diam. $0.35 \mathrm{~mm}$ ) of the nickel-rich nickel-titanium containing 50.9 at $\%$ Ni (Memry Corp. USA) were used in this study. During the manufacturing (drawing) the wire was subjected to a $\sim 40 \%$ cold-work with $5 \%$ increments with no heat treatment in final step. On as-reseived material two different heat treatments were applied in order to obtain certain crystallographic structures in the samples to be studied. The first set of wires were solution annealed at $850^{\circ} \mathrm{C}$ for 60 minutes followed by aging treatment at $450^{\circ} \mathrm{C}$ for 30 minutes (these samples are later addressed with SA). For the second set only aging treatment at $450^{\circ} \mathrm{C}$ for 30 minutes was carried out without any prior solution annealing treatment (samples marked with $\mathbf{A}$ ). In both cases, after each heat treatment, samples were quenched in $25^{\circ} \mathrm{C}$ water. Solution annealing treatment was conducted in a vacuum quartz tube in the presence of titanium powders in order to minimize the effect of oxidation. Aging treatment was carried out in argon atmosphere.

\subsection{Differential scanning calorimetry (DSC)}

The transformation behavior during heating and cooling was investigated using a differential scanning calorimeter Netzsch DSC 200F3. The DSC samples with masses between 20 and $40 \mathrm{mg}$ were heated up to $100^{\circ} \mathrm{C}$ where they were held for three minutes to establish thermal equilibrium. Then the DSC measurement started by cooling down to $-100^{\circ} \mathrm{C}$ in $10^{\circ} \mathrm{C} / \mathrm{min}$. At $-100^{\circ} \mathrm{C}$ the samples were again held for three minutes and then heated up to $100^{\circ} \mathrm{C}$ with a heating rate of $10^{\circ} \mathrm{C} / \mathrm{min}$.

\subsection{Tensile tests}

Tensile test samples were cut to $90 \mathrm{~mm}$ length and the extensometer gage length was set to $70 \mathrm{~mm}$. To evaluate the super-elasticity in loading/unloading and the ability of the wires to recover deformation in macroscale, tensile tests were carried out at room temperature $\left(27^{\circ} \mathrm{C}\right)$ up to $7 \%$ strain (Zwick/Roell FR010). To prevent effect of heating the samples due to phase transformations during the test, the strain rate was set to $0.2 \mathrm{~mm} / \mathrm{min}$ (e.g. static condition).

\subsection{Nanoindentation}

The samples for the nanoindentation were made by mounting and mechanical polishing of cross section of wires with $0.5 \mu \mathrm{m}$ diamond paste. The mechanical polishing was done with applying very low load to minimize the surface plastic deformation and keeping for longer duration for removing the deformed layer as much as possible. Hysitron TriboindenterII, a nanoindentation instrument (USA) with Berkovich diamond tip $\left(\mathrm{E}_{\mathrm{i}}=1140 \mathrm{GPa}, \mathrm{v}_{\mathrm{i}}=0.07\right.$, tip radius $\mathrm{R}=230 \mathrm{~nm}$ ) was used for the nanoindentation tests in which the load-displacement response of the sample was recorded. All indentation tests were carried out in load-controlled condition. Four indents with maximum load of 40, 80, 100 and $300 \mu \mathrm{N}$ were made with 15 seconds elapsing time at the maximum load. Nanoindentation instrument was equipped with atomic force microscope (AFM) that enables us to study the surface before and after indentation with high resolution.

\section{Results and Discussions}

\subsection{Phase transformations}

Fig. 1 depicts the DSC graphs of both (A) and (SA) samples. The A sample (Fig. 1b) that was aged exhibits apparently only one peak during cooling and two peaks during heating. $\mathrm{M}_{\mathrm{s}}=37^{\circ} \mathrm{C}, \mathrm{M}_{\mathrm{f}}=15^{\circ} \mathrm{C}, \mathrm{A}_{\mathrm{s}}=22^{\circ} \mathrm{C}$ and $\mathrm{A}_{\mathrm{f}}=40^{\circ} \mathrm{C}$. The solution annealed and aged, SA, sample (Fig. 1a) shows three-step transformation in the cooling regime $\left(\mathrm{M}_{\mathrm{s}}=-22.5^{\circ} \mathrm{C}\right.$, $\mathrm{M}_{\mathrm{f}}=-43^{\circ} \mathrm{C}, \mathrm{R}_{\mathrm{s}}=37.5^{\circ} \mathrm{C}$ and $\mathrm{R}_{\mathrm{f}}=23^{\circ} \mathrm{C}$ ). In a binary NiTi alloy, two martensitic phases can be formed on cooling: the first transformation from the cubic high temperature phase (B2) to the rhombohedral $\mathrm{R}$ phase, while further cooling results in transformation $\mathrm{B} 2+\mathrm{R} \rightarrow \mathrm{B} 19^{\prime}[7,8]$. The first R-phase transition is associated with $1 \%$ transformation strain, while formation of the $\mathrm{B} 19^{\prime}$ is associated with $10 \%$ transformation strain. The possible precipitates and dislocations in the structure promote the R-phase as they act as barriers to formation of B19' [9]. In sample SA solution annealing has led to the recrystallization of the material and releasing the dislocation structure formed during drawing of the wire, and with applying secondary heat treatment (aging) the precipitates will be introduced into the microstructure and consequently R-phase formation will be favored. However, in Sample A the aging temperature has not been high enough to cause the recrystallization and releasing the dislocation structure, and the observed one transformation peak is 
related to the $\mathrm{B} 2 \rightarrow \mathrm{R}$ and $\mathrm{B} 2 \rightarrow \mathrm{B} 19^{\prime}$ transformations that the peaks are overlapped. This explanation is plausible due to presence of two peaks in heating of the A Sample.

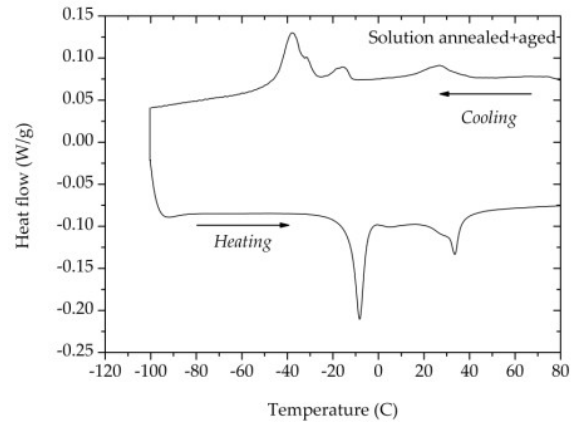

a)

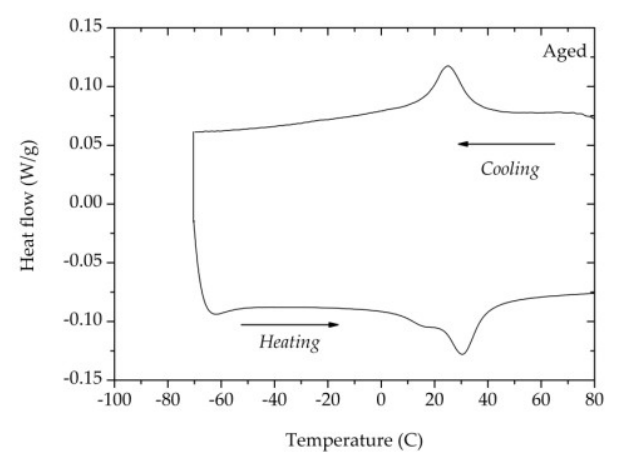

b)

Fig.1. DSC curves for the wire with a) the SA treatment, and b) the $\mathbf{A}$ treatment.

Fig. 2 shows the optical microstructure of the solution annealed SA Sample. The grains are not any more oriented according to the deformation direction of drawing as in the A Sample and the grain size is significantly larger than asreceived wire (the microstructure is not presented here due to limitation of optical image that can not show the fine grains in that range).

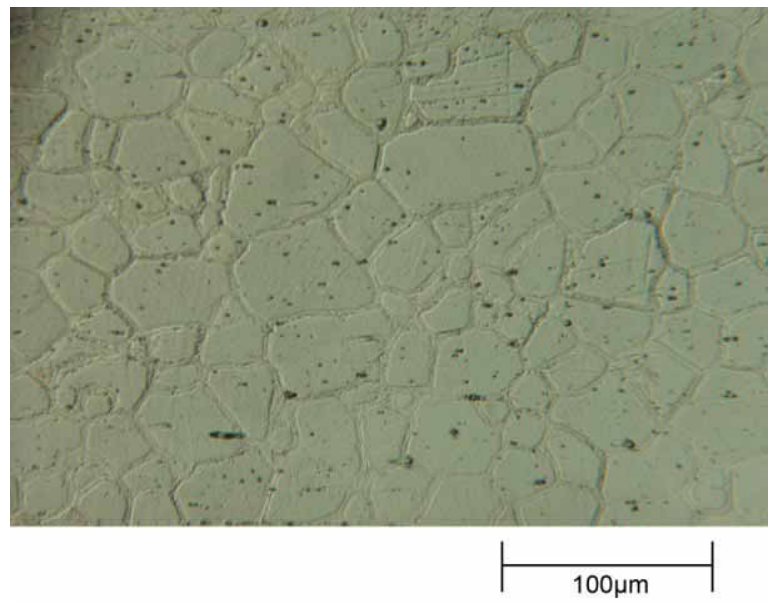

Fig.2. Microstructures of the SA Sample.

\subsection{Tensile behavior}

Figure 3 shows the tensile test results of SA and A samples at room temperature. The SA sample at testing temperature has a microstructure mixture of austenite and R-phase. Due to solution annealing which decreases the dislocation density the critical shear stress for slip is low. However, two deformation mechanisms might be considered; i) deformation due to slip and ii) deformation due to twinning. In the loading there is a linear elastic region followed by a nonlinear region right before the starting of the plateau. The nonlinearity might be due to austenite to R-phase transformation. In the transition from nonlinear to plateau there was no stress-peak observed which can be an indication of different stress-induced transformations such as B2 $\rightarrow$ B19'and R $\rightarrow$ B19'. Also, increasing the slope of plateau can be an indication of deformation by slip mechanism and there is no distinct region indicating martensite plasticity. The scenario seems more plausible while in unloading we have partial recovery. The mechanism responsible for the recovered portion of deformation is reverse transformation of twinned martensite. The residual strain can be an indication of deformation mechanism associated with slip or can be related to the presence of R-phase in the testing temperature. The aged sample at testing temperature had the microstructure mixture of austenite and martensite. The stress-strain curve of aged sample can be divided into three regions. In the first region there is elastic deformation of austenite phase (and some elastic-plastic deformation of existing martensite) followed by a maximum stress peak which is starting point of austenite to martensite transformation. The last portion of loading part consists of the elastic and/or plastic deformation of martensite. 


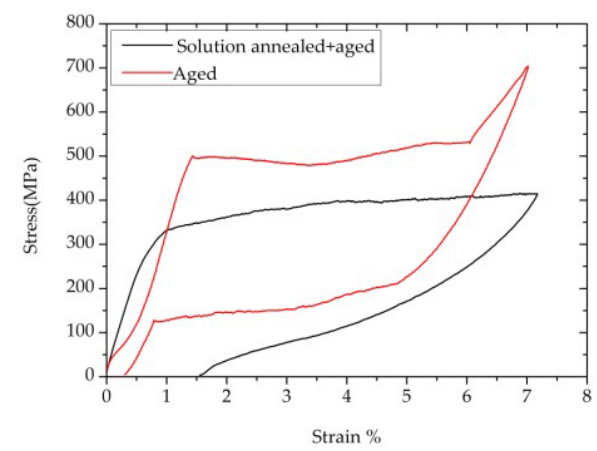

Fig. 3. The tensile test results of the $\mathbf{A}$ (red line) and SA (black line) samples at room temperature.

\subsection{Nanomechanical behavior}

Figure 4 shows the load-displacement response of both A and SA Samples under different maximum loads. Disregarding of the sample and maximum applied loads, in all cases discontinuities (sudden increase in depth) during the loading were observed. Nevertheless, there were no significant discontinuities observed in unloading (except for $100 \mu \mathrm{N}$ A sample). Discontinuities (or "pop-ins") in loading portion are shown by arrows in figure 4. For some of the conventional metals it has been shown that discontinuities in the loading portion of nanoindentation is an indication of dislocation nucleation and/or movement [10]. Nevertheless, in this experiment, for the aged sample, A Sample, such explanation is not valid as the final depth of indent for the indents with maximum load, equal or smaller than $100 \mu \mathrm{N}$ is close to zero and there is no trace of permanent deformation on the surface of material. In this case we can consider that observed pop-ins (particularly for 40,80 and $100 \mu \mathrm{N}$ indents for " $\mathrm{A}$ " sample) are related to stress induced martensitic transformations (SIM).

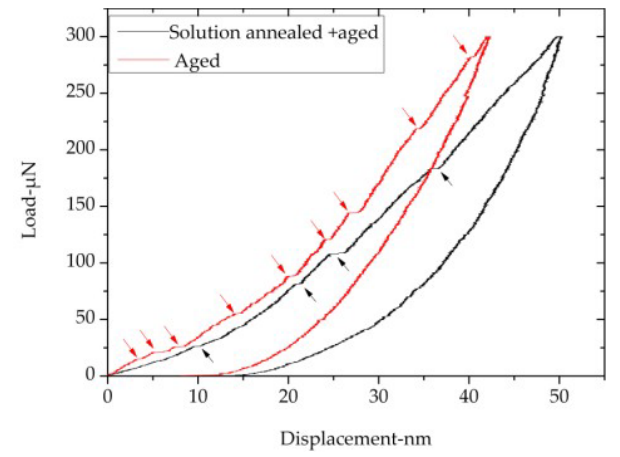

a)

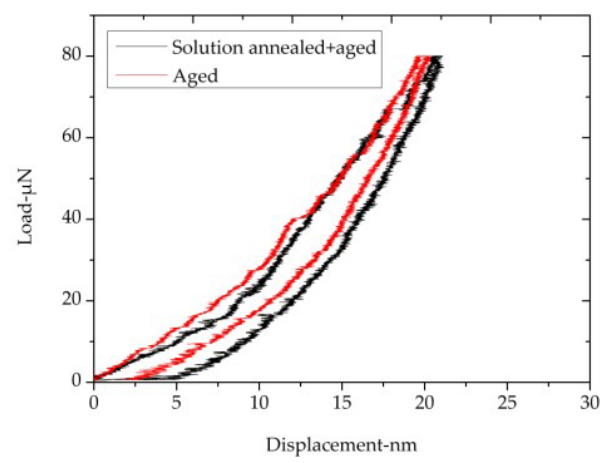

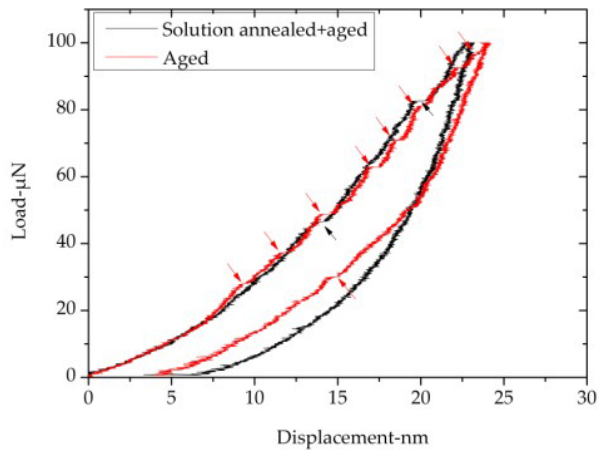

b)

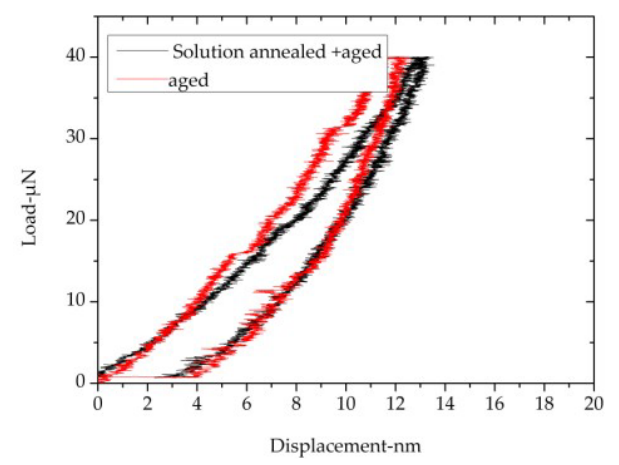

c)

d)

Fig. 4. The load-displacement response in the nanoindentation study of both the A (red) and SA (black) Samples under a) $300 \mu \mathrm{N}, \mathrm{b}$ ) $100 \mu \mathrm{N}$, c) $80 \mu \mathrm{N}$ and d) $40 \mu \mathrm{N}$ load.

The full recovery of A Sample was also observed in tensile test. Due to full recovery of indents in A Sample (40, 80 and $100 \mu \mathrm{N}$ indents) reverse transformation must be happened. However, we did not observe any significant 
discontinuity in the unloading portion as Frick et al. [11] reported. But for the A Sample sudden slope change of unloading curve was observed in 100 and $80 \mu \mathrm{N}$ maxmimum loads. We hypothesize the sudden slope change of unloading portion is an indication of reverse martensitic transformation. This explanation is plausible while there is not any known phenomena related to reverse dislocation movement upon unloading. By comparing the load-displacement response for both samples, it is clear that the number of pop-ins in the A Sample is more than that of SA Sample. This is in agreement with the tensile test behavior of these materials. As the SA Sample did not show clear superelasticity because of the presence of R-phase in the material at the beginning of the tests which restricts partially the stressinduced martensitic transformation. Also due to the large grain size $(\sim 40 \mu \mathrm{m})$ one grain was indented in this material. The A sample had significantly finer grains $(<<1 \mu \mathrm{m})$ and with increasing the indent load more grains undergo stress induced martensitic transformation. Figure 5 shows the atomic force microscope (AFM) image of the A sample before and after nanoindentation. No indent mark was observed for indents with 40, 80 and $100 \mu \mathrm{N}$ maximum load. The only visible indent mark is made by indent with $300 \mu \mathrm{N}$ load.

In figure $5 \mathrm{~b}$, for the SA Sample in addition to the indent marks also a surface phenomena was observed as some surface asperities after nanoindentation (Fig. 5b). This might be related to permanent martensites which were formed during the nanoindentation and due to very smooth surface of sample (less than 10nm) became visible under AFM. However, such phenomenon was not observed in all indents. We assume the formation of asperities strongly depends on the location of indent. Another surface related observation was reported for shape memory CuAlNi which was very limited to the vicinity of nanoindentation mark [12]. To deeply understand the origin of this phenomenon, further studies are needed with having the knowledge of indenting spot and crystallographic orientation. Additionally, a nanoindentation stage with capability of heating can be used to verify the martensitic transformation which can be reverted upon heating.
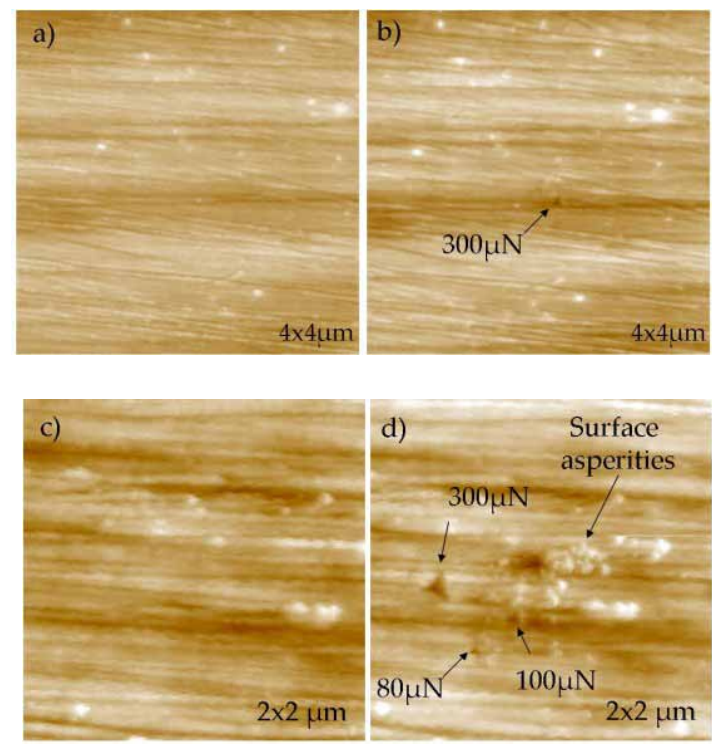

Fig. 5. AFM image of the A Sample a) before and b) after nanoindentation test showing nearly full recovery of the indentation marks except for $300 \mu \mathrm{N}$ indent; and the SA Sample c) before and d) after nanoindentation presenting surface asperities after the indentation test.

Fig.6a shows the schematic diagram for the indentation of NiTi shape memory alloys which illustrates different information given by the indentation curve, such as hardness, energy dissipation and energy recovery (adopted from Gall et al. [13].) The recoverable energy, $\mathrm{E}_{\mathrm{r}}$, will be higher if a significant reverse transformation or lattice relaxation takes place upon unloading. Fig. $7 \mathrm{~b}$ shows the calculated $\mathrm{E}_{\mathrm{r}}$ values (percentile) for the $\mathbf{A}$ and $\mathbf{S A}$ Samples at different maximum loads. With the loads 300, 100, and $80 \mu \mathrm{N}$ the maximum recoverable energy is obtained for the A Sample, while recoverable energy is clearly lower for the SA sample. Observed higher recoverable energy in the A Sample is suggested to be related to the larger amount of the recovered stress-induced martensite in this material during unloading. Additionally, immobilized dislocations by the small grain size, possible residual deformation structure from the wire drawing, and perhaps also by the precipitates in the structure, result in large elastic strain which is recoverable. In the SA sample the dislocation structure is minimized and the grain size is larger, due to solution annealing, both minimizing the barrier for dislocation movement and resulting in permanent plastic strain. Furhermore, as the amount of austenite for SIM transformation in this material was less than in the A Sample, it may be that also the amount of recovering SIM is less. In addition, the high dislocation activity stabilizes the martensite plates and reducing further the $E_{r}$ in SA Sample. The recoverable energy for both samples increased with decreasing the maximum indentation load 
from 300 to $80 \mu \mathrm{N}$. As the applied stress decreases, the possible permanent slip deformation of the structure should decrease. Therefore, this behaviour may indicate that the main part of the observed recoverable energy originates from the reverse SIM transformation. However, by further decreasing the maximum load to $40 \mu \mathrm{N}$, the $\mathrm{E}_{\mathrm{r}}$ values for both the A and SA Samples decrease. In the A Sample, recoverable energy decreases from $72.6 \%$ to $60 \%$, while the decrease in the SA Sample is only couple of percentages. This may be related to the higher stress level needed for the SIM formation in the A sample, e.g. with the lower applied stress, the amount of the SIM to be formed is less, and consequently, the recoverable energy related to the reverse transformation is also smaller.

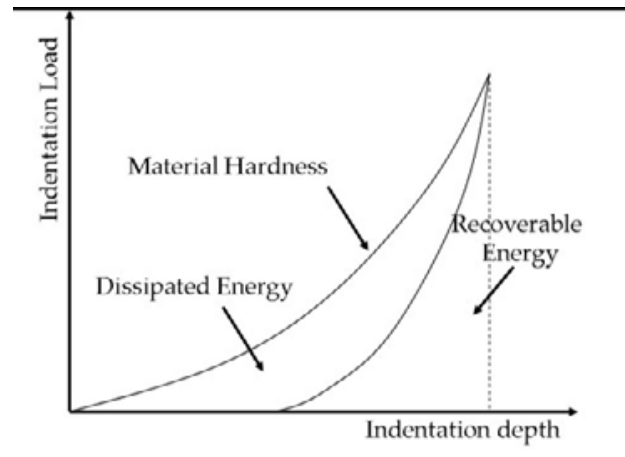

a)

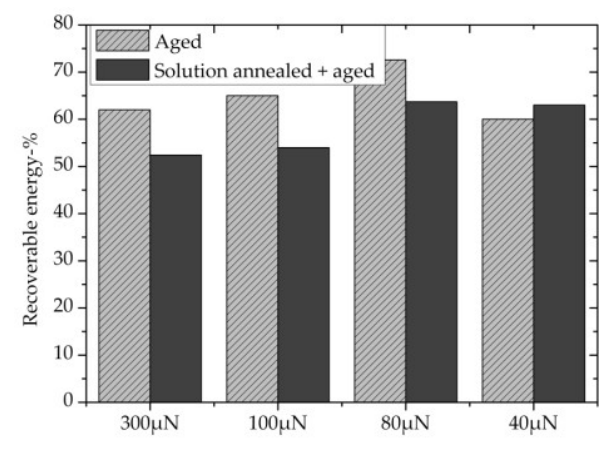

b)

Fig.6. a) Information obtained from the indentation curve according to Gall et al. [13]. b) Recoverably energy ( $\left.\mathrm{E}_{\mathrm{r}}\right)$ for the $\mathbf{A}$ (dashed) and SA (black) Samples with applied maximum indentation loads of 300, 100, 80 and $40 \mu \mathrm{N}$.

\section{Conclusions}

The difference in tensile behavior of SA and A Samples was addressed by critical slip stress and presence of different dominant microstructures such as austenite and R-phase which leads to improved and poor superelasticty respectively. Discontinuities in loading and sudden slope change in unloading portion of P-h curves were attributed to the SIM and reverse SIM transformations respectively. Recoverable energy was measured as a mean to ability of material to undergo the reverse SIM transformation. A new surface related asperities phenomenon was reported which was visualized by AFM imaging before and after nanoindentation.

\section{Acknowledgements}

AG is grateful for constructive discussions with Professor Gouldstone from Northeastern University, Department of Mechanical, Industrial and Manufacturing Engineering, and Professor Frick from Wyoming University, Department of Mechanical Engineering.

\section{References}

[1] P. Krulevitch et al., J. MEMS 5, 271 (1996).

[2] K. Bhattacharya, R.D. James. Science 307, 53 (2005).

[3] A. Gouldstone, H.-J. Koh, K.-Y. Zeng, A.E. Giannakopoulos, S. Suresh, Acta Mater. 48, 2277 (2000).

[4] G.A. Shaw, W.C. Crone, Mat. Res. Soc. Symp. - Proc. 791, 215, (2003).

[5] K.S.S.E. Raju, S, Bysakh, M.A. Sumesh, S.V. Kamat, S. Mohan, Mat. Sci. Eng. A, 476, 267 (2008).

[6] A. Kumar, D. Singh, D. Kaur, Surf. Coat. Techn. 203, 1596 (2009).

[7] J. Khalil Allafi, X. Ren, G. Eggeler, Acta Mater. 50, 793 (2002).

[8] M.C. Carroll, Ch. Somsen, G. Eggeler, Scripta Mater. 50, 187 (2004).

[9] J. Khalil-allafi, A. Dlouhy, G. Eggeler, Acta Mater. 50. 4255 (2002)

[10] T.F. Page, W.C. Oliver, C.J. McHargue, J Mater Res 7, 450 (1992).

[11] C.P. Frick, T.W. Lang, K. Spark, K. Gall, Acta Mater. 54, 2223 (2006).

[12] W.C. Crone, H. Brock, A. Creuziger, Exp. Mech. 47, 133 (2007).

[13] K. Gall, K. Juntunen, H.J. Maier, H. Sehitoglu, Y.I. Chumlyakov, Acta Mater. 49, 3205 (2001). 